\title{
APLICABILIDADE, CONTROLE E TRANSPARÊNCIA NAS AÇÕES DA ADMINISTRAÇÃO PÚBLICA BRASILEIRA
}

\author{
Roberta Di Paula Menezes ${ }^{1}$
}

RESUMO: O presente trabalho é sobre a aplicabilidade, controle e transparência nas ações da administração pública brasileira. Perante muitas discussões procura-se mostrar as vertentes do "ser legal" das organizações públicas em um ambiente vasto da administração. Pode-se concluir que a Administração Pública, tem a função de efetivar o princípio da publicidade e estimular a participação dos cidadãos no julgamento das contas públicas em que o Tribunal de Contas da União é o órgão fiscalizador que coíbe eventuais desvios de recursos, visando a transparência administrativa. Os documentos analisados reforçam a importância da transparência como resultante do trabalho efetivo do sistema de controle externo. Para que haja qualquer mudança se busca sempre a referência da legalidade para a sua implantação de imediato ou gradativo de acordo com o grau de impacto na vida da sociedade, de forma transparente e o mais simples para o entendimento de todos, sobre quaisquer mudanças realizadas no meio público desde as realizações de serviços e atos. Neste contexto, o presente artigo é resultado de uma pesquisa com o objetivo de analisar a importância do controle externo, aplicabilidade da legalidade e transparência no planejamento e execução de ações na organização pública. Todavia, a utilização de pesquisa bibliográfica fundamentado no Direito Administrativo, tendo o limite temporal da Constituição Federal de 1988 e da Lei de Responsabilidade Fiscal. Para dar veracidade e sustentabilidade teórica ao estudo foram usados estudos de autores renomados da área da Administração Pública.

Palavras-Chave: Administração Pública. Aplicabilidade e Transparência. Controle Externo.

\section{INTRODUÇÃO}

O terreno das políticas de controle tem sido explorado sucessivamente nos últimos anos. Tanto que a sociedade começa a reconhecer que os agentes públicos devem ser

\footnotetext{
r Graduada em Administração de Empresas pelo Centro Universitário Estácio da Amazônia. E-mail: dipaulan@gmail.com.
} 
responsabilizados por suas atividades e prestar contas de seus atos aos cidadãos ou a instituições especializadas. Isso constitui uma característica fundamental dos sistemas democráticos, no quais os mecanismos de controle se situam.

Essa inquietação moderna sobre a gestão pública levou o legislador brasileiro a adotar, no mundo jurídico, as bases para o atual Estado Democrático de Direito da Constituição Federal de 1988, modificando a estrutura das relações entre a Administração Pública e os administrados.

Nesse quadro, a pesquisa sobre o tema "Controle externo da Administração Federal como instrumento para alcançar transparência" encontrou terreno fértil para mostrar esse momento em que o cidadão está mais consciente de seu papel e encontra ferramentas para apoiá-lo na fiscalização da atividade do governo.

Partindo desse postulado, iniciamos o presente estudo, buscando dissecar os meandros, conceitos e fundamentações dos controles externos, com ênfase na transparência administrativa no trabalho da instituição Tribunal de Contas da União - TCU, alcançando, por esse caminho, o administrador público em sua práxis, observando, também, o liame necessário entre o comando constitucional/legal e a gestão efetiva da coisa pública.

Importa destacar a imposição de um limite temporal, ou seja, a Constituição Federal de 1988, como ponto base para o estudo, ainda que se valha de outro marcos como a o Decreto Lei 200, a Lei de Responsabilidade Fiscal, tudo para melhor situar o controle externo e trazer um histórico da Instituição do Tribunal de Conta da União, como executor do poder/dever de fiscalizar a aplicação dos recursos da União, ainda que sob a batuta do Poder Legislativo nessa missão constitucional.

Tendo em vista os princípios norteadores da administração pública, a saber: os da legalidade, legitimidade, economicidade e transparência, parâmetros constitucionais que limitam o gestor público quando ao tomar e executar suas decisões, este não poderá ultrapassar a barreira imposta pelo ordenamento jurídico, sob pena de responsabilização.

Dentre esses princípios os mais importantes são, sem dúvida, o da legalidade - que busca a verificação da obediência dos atos administrativos aos mandamentos preconizados 
em lei; e o da legitimidade - que afere a regularidade do ato, tratando-se tais sujeições de fundamento do Estado Democrático de Direito.

A metodologia do presente artigo é de cunho bibliográfico, qualitativo e descritivo em que a metodologia desta pesquisa parte da análise e questionamento sobre a aplicabilidade, controle e transparência nas ações da Administração Pública brasileira que tem seus fundamentos jurídicos no Direito Público, com raízes no Direito Administrativo e está voltada para aclarar os conceitos de aplicabilidade e transparência administrativa, aqui muitas vezes tratada como transparência pública.

Desenvolvem-se reflexões sobre o princípio da transparência na administração pública, seus conceitos mais usuais, o entendimento doutrinário sobre a temática. Em seguida tem-se um capítulo sobre o controle externo como instrumento de transparência, em que aborda normas constitucionais sobre a atuação do TCU na execução de suas atribuições.

Traz-se ainda, um capítulo sobre a efetivação do controle externo e sua relação com a transparência; passando-se em seguida às considerações finais sobre o tema, numa análise que permita apresentar à sociedade o modo como está sendo fiscalizado o emprego do dinheiro do contribuinte na gestão pública.

Objetiva-se, com este trabalho, a elaboração de uma referência que contribua para a orientação dos administradores públicos, agentes políticos, assessores, servidores, advogados, acadêmicos e, quiçá, do cidadão comum, no entendimento e implementação do controle social.

Para que haja qualquer mudança se busca sempre a referência na legalidade para a sua implantação de imediato ou gradativo de acordo com o grau de impacto na vida da sociedade, de forma transparente e o mais simples para o entendimento de todos, sobre quaisquer mudanças realizadas no meio público desde as realizações de serviços e atos.

Em busca de uma nova perspectiva sem deixar de lado a normatização do Art. 37 da constituição federal que deixa explícita a sua legalidade, moralidade, publicidade e a eficiência das instituições para manter-se transparente com seus atos para com todos, diretos 
ou indiretamente afetados por qualquer mudança implantada deixando sempre de forma clara o seu real objetivo.

\section{REFERENCIAL TEÓRICO}

\section{I A TRANSPARÊNCIA NA ADMINISTRAÇÃO PÚBLICA}

A Constituição Federal de 1988 dedicou a constitucionalização dos preceitos básicos do Direito Administrativo ao antever que a Administração Pública direta e indireta de qualquer dos Poderes da União, dos Estados, do Distrito Federal e dos Municípios obedecerá aos princípios de legalidade, impessoalidade, moralidade, publicidade e eficiência; além dos preceitos básicos distribuídos nos 2I incisos e io parágrafos do art. 37 e das demais regras previstas nos art. 38 a 42 daquele instituto.

A constitucionalização do Direito Administrativo, que legisla diretrizes para a Administração Pública, foi objeto de pesquisa do Professor Alexandre de Morais, em que mostrou a remota origem, "ao final do século XVIII, início do século XIX”, o nascimento do Direito Administrativo como ramo autônomo do Direito, cindindo-se do Direito Civil, ramo que estabelecia até então esparsas normas administrativas a serem cumpridas pelo Poder Público, bem como as funções, os cargos e a estrutura administrativa.

Isso acarretou para a Lei Maior a afirmação do Estado Democrático de Direito, que lançou novos rumos sobre as estruturas do relacionamento entre Administração Pública e os seus administrados, permitindo assim caminhos mais abertos para um novo entendimento sobre o princípio da legalidade na execução da atividade administrativa.

Os princípios ali aprovados são altamente acentuados para se conseguir uma clara definição de interesse público e afiançam que a busca por uma Administração competente não é mais privilégio exclusivo da própria Administração. $O$ cidadão quer, e tem o direito de participar mais ativamente das decisões, não como simples plateia distanciado do poder, mas como destinatário da atuação das entidades e órgãos administrativos.

Com a abertura desse caminho ficou mais clara a possibilidade de participação do povo na tomada de decisões administrativas, o que permite um maior grau de 
correspondência entre as demandas sociais e as ações administrativas. Diante desse esforço, foi indispensável proceder a uma maior importância da publicidade das ações da Administração, incrementando os níveis de conhecimento e fiscalização, e uma suficiente explicação dos motivos que orientam as decisões. Com isso, cria-se maior visibilidade do governo perante a sociedade, e permite-se o conhecimento e a aceitação de atos legítimos, bem como a reação imediata aos atos imorais e ou desproporcionais.

A utilização dos princípios da publicidade, motivação e participação popular apontam para a existência do princípio da transparência a orientar as atividades da Administração Pública que, no ensinamento do professor Martins Júnior (2004), tem como elemento mais caracterizador facilitar o exame da observância dos princípios que regem a administração pública quais sejam: da legalidade, da impessoalidade, da moralidade, da eficiência, da proporcionalidade, além de tratar-se de um processo que incide sobre a própria legitimidade do uso do poder.

Esses princípios, aliados às tecnologias da informação, permitem o que se convencionou chamar de transparência pública. Isso faz com que o cidadão acompanhe os processos decisórios e que o próprio administrador, ou responsável, tenha uma visão do valor financeiro de determinado projeto, dos recursos de que disporá efetivamente, sem falar da impressionante flexibilidade no uso final dos recursos. Assim, tanto a sociedade adquire capacidade de controle, como o responsável tem instrumentos adequados de gestão físicofinanceira.

Em comentário sobre transparência, ensina Evandro Martins Guerra (2003, p. 9I): Importante notar que a transparência aparece na lei como mecanismo mais amplo que o já previsto princípio da publicidade, posto que este prevê a necessidade de divulgação das ações governamentais, ao passo que aquele determina, além da divulgação, a possibilidade de compreensão do conteúdo, ou seja, a sociedade deve conhecer e entender o que está sendo divulgado.

A constitucionalização das regras básicas da Administração Pública buscou a neutralidade do aparelho estatal, a fim de coibir, sobretudo, o Poder Executivo de manipulálo com descabimento capaz de comprometer objetivos do Estado de Direito. Isso porque na 
vivência prática dos direitos fundamentais, é o Poder Executivo, ou melhor, o administrador público que tem o papel de vilão.

Poder-se-ia afirmar ainda que a atual Constituição da República trouxe para seu texto as principais normas do Direito Administrativo prevendo normas de gerência, contratação, publicidade, entre outras; além do Estatuto do Servidor Público e de mecanismos de controle da Administração.

A codificação constitucional das normas administrativas visa a dar uma orientação mais segura aos rumos da condução da Administração Pública, tendo como finalidade limitar o poder estatal, prevendo instrumentos de controle e meios de responsabilização dos agentes públicos, para garantia de transparência, probidade administrativa para o combate à corrupção. Como informa Alexandre de Morais (2002. p. 99) a constitucionalização dos princípios básicos da Administração Pública tem a mesma finalidade: garantir a honestidade na gerência da res pública e possibilitar a responsabilização dos agentes públicos que se afastarem dessas diretrizes obrigatórias.

Segundo Nunes (2013, p. 31), "a prestação de contas por parte das entidades públicas, para alcançar seu objetivo de repassar ao cidadão informação sobre os custos e investimentos do governo, deve ser transparente, característica que pressupõe informações acessíveis, compreensíveis e úteis aos cidadão".

Segundo Oliveira (2012), o Brasil ficou em 69- lugar no índice de percepção da corrupção, calculado pela ONG Transparência Internacional. Cabe destacar que essa análise foi realizada entre 176 países, sendo que o Brasil atingiu uma nota de 43 pontos, em uma escala de o (mais corrupção) a ıoo (menos corrupção).

De acordo com os autores Nunes (2013) e Oliveira (2012), quanto há pouca transparência na gestão pública, a legalidade está sendo infringida pelos gestores públicos, logo seu processo está sendo afetado pela falta de transparência e a sociedade como um todo é diretamente afetada.

Conforme Lacerda Et al. (2012), a auditoria governamental contempla um campo de especialização da auditoria, voltada para o patrimônio e o interesse público. É uma atividade de avaliação voltada para o exame, visando à comprovação da legalidade e 
legitimidade, bem como adequação dos resultados obtidos quanto aos aspectos da eficiência, eficácia e economicidade.

\subsection{TRANSPARÊNCIA E SUA IMPORTÂNCIA COMO FERRAMENTA DE CONTROLE}

O conceito de transparência abrange mais que o princípio da publicidade previsto na Carta de 1988. Um elemento que se mostra importante para caracterizar a transparência é a possibilidade de participação do cidadão nas decisões, permitindo que se conheça como se gasta os recursos obtidos da sociedade.

Outro elemento a ela relacionado é a obrigação que o governo tem de prestar contas sobre seus atos, sobretudo os que envolvem gastos. Essa prestação de contas permite à sociedade sintetizar as informações sobre o governo e emitir um juízo de valor sobre as ações governamentais. Para isso, cada vez mais o governo deve utilizar-se dos meios de comunicação, sobretudo os eletrônicos, que tendem a facilitar a divulgação oficial.

Como as ações do governo são pautadas exclusivamente por leis, os gastos públicos não fogem à regra. As leis orçamentárias direcionam os gastos do governo; com isso, a participação popular no processo orçamentário é de extrema importância, visto que o governo se resume aos instrumentos jurídicos para executar seus objetivos.

O entendimento de que a Administração Pública atual reflete os anseios da sociedade por uma especialização no aprestamento dos serviços e uma racionalização dos recursos é o que se afere do ensinamento do Professor Luís Carlos Bresser Pereira (1997).

Dentre as reformas cujo objetivo é majorar governança ou capacidade de governar a aptidão efetiva de que o governo dispõe para decompor suas políticas em realidade - as que primeiro foram começadas, ainda nos anos 80 , foram aquelas que restabelecem saúde e autonomia financeira para o Estado: individualmente o ajuste fiscal e a privatização. Porém antes admirável é a reforma administrativa que torne o serviço público coerente com o capitalismo atual, que admita aos governos corrigir as falhas do mercado sem incorrer em falhas maiores. Este tipo de reforma vem auferindo crescente atenção nos anos 90. 
Existe uma explicação para isto em que os cidadãos estão tornando-se cada vez mais cônscios de que a administração pública burocrática não retribui às demandas que a sociedade civil apresenta aos governos por ela eleitos, no capitalismo democrático atual. Consegue-se que os cidadãos tendem a exigir do Estado muito mais do que o Estado pode fornecer.

Esse espaço entre demandas e possibilidade de oferta por parte do Estado está na origem não apenas da crise fiscal, como observou O'Connor (1973), e da crise de governabilidade, como apartou Huntington (1968), todavia também da crise da administração pública burocrática. Os recursos econômicos e políticos são, por definição, insuficientes em relação à demanda, e se tornam ainda mais escassos quando a administração pública é ineficiente.

Todavia, quando não se pode contar com o mercado, quando a alocação de recursos pelo mercado não é solução factível, dado seu caráter levado ou dada sua incompletude, a essência de uma administração pública hábil passa a ter valor ardiloso ao reduzir a lacuna que separa a demanda social e a satisfação desta demanda.

Segundo o Professor Bresser Pereira segue abonando que a participação de usuários na gestão e controle de instituições públicas é um aparelho que pode resolver problemas da relação principal-agente entre políticos e burocratas. Os usuários dos serviços públicos podem assessorar os políticos na supervisão e abonar a prática eficiente das políticas por eles definidas, pois detêm informações sobre o desempenho dos burocratas.

Contudo, os cidadãos, para os quais os serviços públicos são separados, têm informações sobre o desempenho dos burocratas na prática de políticas públicas que podem ser usadas pelos políticos para definir os problemas da relação principal-agente com os burocratas. Com base nas informações dos usuários dos serviços públicos, o principal (político) pode controlar o agente (PEREIRA, 1997).

Advertir que há uma preocupação dos doutrinadores sobre as demandas sociais de ajuste entre o que se arrecada e a aplicação razoável desses recursos, com vista a um maior aproveitamento social. O controle oficial, o sistema de controle estabelecido na Constituição, é o principal veículo de visibilidade do governo e a divulgação dos gastos 
contribui para o alcance da transparência administrativa, sendo o meio eletrônico o que universaliza melhor as informações sobre os entes públicos que ultrapassam os limites dos gastos orçados.

Esse conhecimento é sintetizado pela sociedade que reage conforme o grau de insatisfação com a gestão pública, o que é sadio no regime democrático. Isso reflete no conceito que se tem dos gestores públicos contribuindo, seguramente, para o processo em que o controle social se apresenta como eficiente regulador dos atos do administrador público.

Segundo Trosa (200I), a pressão para prestar contas cresce, pode vir do poder político. Tem uma preocupação dos governos em ver seus objetivos efetivamente realizados, o corolário é a obrigação organizada de prestar contas ela pode vir dos próprios funcionários. A crise de legitimidade do Estado defende a transparência: as administrações elegem prestar contas a se verem fixamente atacadas. Ela pode vir do orçamento. As estruturas orçamentárias recaem cada vez mais repetidas, sobre as alegorias de atuação e de resultado. Pode o serviço público adolescer o ajuste sem ficar obrigado a uma maior transparência? Que os agentes públicos possam apresentar contas em termos qualitativos e quantitativos sem medo de serem censurados, se sua expressão no caso tiver sido razoável.

Concluir que a exigência para que haja uma administração confiável tem diversa origens na sociedade, e cabe ao gestor, que espera aprovação para seus atos, apresenta seus feitos demonstrando o seu grau de comprometido com a coisa pública, com isso, contribuir cada vez mais com a consolidação do estado democrático de direito, no qual o povo é o legítimo titular do poder.

Com efeito, os princípios jurídicos são os principais indutores das atividades administrativas, com base no alcance da dimensão principiológica que pode ser caracterizada tanto pela função negativa (proibição de uma conduta) quanto pela função positiva (imposição de determinado comportamento para verificação prático-jurídica de sua finalidade). Ambas servem à invalidação de ato jurídico transgressor, no benefício da relativa dose de indeterminação da função positiva, se concebida com a influência exercida sobre o conteúdo da regulação de sucessivas decisões. 
Para se entender transparência como princípio, recorre-se à a nálise da positivação ou não dos princípios, nas questões de princípios implícitos e explícitos no ordenamento jurídico, tanto é que a validade e aplicação dos princípios jurídicos independem de consagração pelo legislativo (positivação). A obrigatoriedade de serem respeitados habita na harmonia desses princípios com a consciência coletiva e no reconhecimento deles como fonte do direito, da qual se originam as normas mais elementares, independentemente de positivação e de regulamentação. Assim, leciona Wallace Paiva Martins Júnior (2004. p. I2):

A força dos princípios repousa, mercê de sua obrigatoriedade e da presencialidade
normativa, na necessidade de serem observados pela interpretação e aplicação das
regras jurídicas, já que as regras lhes conferem concreção, isto é, são aplicações dos
princípios, ainda que independentes de consagração específica em qualquer
preceito particular. Ademais, os princípios jurídicos vinculam a atividade estatal,
implicando por sua função fundamentadora a perda de eficácia de regras
contrapostas e atos administrativos contrários, podendo ser invocados como
supedâneos imediatos de pretensões jurídicas deduzidas em juízo. Com efeito, a
dimensão determinante dos princípios jurídicos é caracterizada tanto pela função
negativa (proibição de uma conduta) quanto pela função positiva (imposição de
determinado comportamento para verificação prático-jurídica de sua finalidade).
Ambas servem à invalidação de ato jurídico transgressor, mercê da relativa dose de
indeterminação da função positiva, se concebida como a influência exercida sobre
o conteúdo da regulação de sucessivas decisões (MARTINS JÚNIOR, 20o4, p. I2).

Com isso, vê-se que a normatizar os princípios jurídicos transita pela concretização processo em que se densificam normas portadoras de grande abertura, diluindo a indeterminação por meio de regulamento, e que o princípio transparência administrativa enquadra-se nos padrões dos princípios de menor densidade, propondo-se a orientar padrões de comportamento da Administração Pública em diversas situações. Logo, as afirmações de que os princípios podem estar explícitos ou implícitos, coadunam com os escritos de Wallace Paiva Martins Júnior, no seu livro “Transparência Administrativa”, como se vê a seguir:

Sem prejuízo das regras legais que incorporam prescrições mais concretas da transparência administrativa, a abertura que sua própria compreensão como princípio jurídico proporciona e o maior grau de abstração, de generalidades e de indeterminações que ostenta têm forte carga para alterações ou reformulações de comportamentos administrativos tradicionais marcados pela histórica opacidade, de maneira que, diante de situações reveladoras de zonas cinzentas, a tendência deve ser a afirmação do princípio da transparência e da ampliação $d$ seus graus de concretização (MARTINS JUNIOR, 2004, p. 16), 
Não obstante, o mesmo autor apresenta o entendimento de que o princípio da transparência administrativa como sendo um super princípio do qual decorrem três subprincípios quais sejam: publicidade, motivação e participação popular, senão vejamos conforme o conceito abaixo:

\begin{abstract}
A identificação do princípio da transparência administrativa palmilha esse percurso, ligada, em última essência, à ideia-base do Estado Democrático de Direito. Em escala decrescente, o princípio da transparência administrativa é inerente do princípio democrático (princípio fundamental estruturante) e, à míngua de clara e precisa denominação normativo constitucional, resulta como o valor impresso e o fim expresso pelos princípios da publicidade, da motivação e da participação popular, como princípios constitucionais especiais ou subprincípios que a concretizam, uma vez que todos (isolada ou cumulativamente) apontam para a visibilidade da atuação administrativa e inspiram a produção de regras como o direito de petição, o direito de certidão e o direito à informação, tidos como mecanismos constitucionais essenciais no controle jurisdicional da transparência, legalidade, moralidade e proporcionalidade na gestão da coisa pública.
\end{abstract}

Seja qual for o gral de transparência administrativa em um ordenamento jurídico, esta é considerada um dos alicerces básicos do Estado Democrático de Direito e da moderna Administração Pública pelo acesso à informação e pela participação na gestão da coisa pública, diminuindo os espaços reservados ao caráter sigiloso da atividade administrativa - ponto de partida par nichos da ineficiência, do arbítrio e da imunidade do poder (MARTINS JÚNIOR, 2004, p. 17),

Nesse passo, presume-se que transparência não se resume a um ou dois termos como conceito, mas em uma série de assuntos e ações que possam resultar em uma forma de visibilidade do governo pela sociedade. A forma como a população avalia determinada ação é resultado daquilo que o próprio governo deseja mostrar. Isso faz com que o controle externo contribui muito para essa visão social sobre o governo.

Ressalte-se, que a transparência mostrada pelo governo pode não atender ao que a sociedade espera. Essa maneira de se mostrar para a sociedade também serve de instrumento de legitimidade, principalmente nos dias atuais em que o governante já não se subsume de divindades para se justificar, retira da própria sociedade, a quem deve prestar contas, sua legitimidade de poder.

A transparência elevada ao grau de princípio possibilitou que a doutrina a reconheça como pertencente a essa categoria de instituto jurídico. Sua aplicabilidade ganha forma e lugar cada vez mais definido no controle social. Transparência e participação popular na 
gestão pública são fatores determinantes para o controle efetivo da sociedade sobre a gestão dos recursos públicos.

Segundo Guerra (2003), a transparência, no sentido alcançado pela lei, é a qualidade exigida do administrador público pela qual deixa-se evidenciar o sentido desejado em suas ações governamentais; caracteriza-se pela possibilidade efetiva participação da sociedade, além de ampla publicidade das informações referentes à administração da coisa pública. No entanto, vejam-se, ainda, os ensinamentos de Martins Júnior que explica seu conceito de transparência administrativa e os mais variados institutos concretizadores desse instituto tão importante para o Estado Democrático de Direito:

O princípio da transparência administrativa colima, em apertada síntese, a preservação da visibilidade e do caráter público da gestão dos negócios públicos e a atribuição de legitimidade material à Administração Pública (além de juridicização, ética, conhecimento público, crítica, validade ou eficácia jurídica, defesa dos administrados e respeito aos seus direitos fundamentais, controle e fiscalização, convencimento, consenso, adesão, bom funcionamento, previsibilidade, segurança jurídica), sendo instrumental de suas finalidades os subprincípios da publicidade, motivação e participação popular. Seu reconhecimento proporciona a reformulação das relações entre Administração Pública e administrados e é sinal de ruptura com o seu tradicional modelo autoritário, hermético, isolado, unilateral, reservado e sigiloso (2004, p. 35).

Assim, confirma-se a importância da transparência como parte essencial do controle sobre a Administração Pública pelos administrados, ressaltando-se os elementos do Estado Democrático formadores do Estado de Direito.

\subsection{CONTROLE EXTERNO COMO INSTRUMENTO DE TRANSPARÊNCIA}

O legislador brasileiro criou um sistema de acompanhamento das atividades administrativas vinculado ao Poder Legislativo com a função precípua de fiscalizar as ações do Poder Executivo na aplicação dos recursos públicos. Nesse sistema inclui-se o Tribunal de Contas da União, órgão especializado na fiscalização contábil, financeira e orçamentária, como auxiliar do Poder Legislativo.

Para se adequar aos reclames sociais na prestação de contas, na exigência de transparência administrativa e no profissionalismo dos serviços, a Administração Pública brasileira vem desenvolvendo um processo de gerenciamento voltado para resultados, que 
impõe ao executor do controle externo mais dinamicidade e maior interação social, e sem o qual não se chega a bom termo naquilo que propôs o legislador para o controle externo.

O controle é função essencial na verificação dos resultados, pois sua intervenção inibe o abuso de poder, fazendo com que a autoridade administrativa paute a sua atuação em defesa do interesse coletivo, mediante a fiscalização orientadora, corretiva e até punitiva. É, ainda, indispensável para acompanhar a execução de programas de governo e apontar suas falhas e desvios, verificar a correta aplicação das normas e princípios adotados e constatar a veracidade das operações realizadas.

Doutrinariamente, usando dos conceitos da Ciência da Administração, o controle é reconhecido entre as funções administrativas essenciais, a saber: planejamento, organização, direção e controle. Planejamento e controle devem estar em sintonia, pois o planejamento sem controle da execução dificilmente obterá sucesso, assim como o controle sem padrões e objetivos previamente estabelecidos não atuará por falta de objeto (CHIAVENATO, 200o).

Nesse sentido, o controle exerce um papel fundamental no desempenho eficaz de qualquer entidade, no que diz respeito à possibilidade da adoção de medidas corretivas para que o processo se reorganize na direção dos objetivos traçados pela organização. A função controle tem especial aplicação nas entidades públicas, tornando-se mecanismo imprescindível para a consecução dos fins a que se destinam, tendo em vista que os bens e recursos por elas geridos pertencem a toda a sociedade, a qual fez um investimento de forma compulsória e isso faz maior a exigência de resultados satisfatórios às demandas sociais. Assim Guerra ensina:

Controle da Administração Pública é a possibilidade de verificação, inspeção, exame, pela própria Administração, por outros poderes ou por qualquer cidadão, da efetiva correção na conduta gerencial de um poder, órgão ou autoridade, no escopo de garantir atuação conforme os modelos desejados anteriormente planejados gerando uma aferição sistemática (GUERRA, 2003, p. 23).

A Administração Pública vem se profissionalizando na prestação de serviços e essa evolução pode ser compreendida como a evolução da Administração Pública, que retira sua força da própria Constituição Federal e seus conceitos da Ciência da Administração inspirada na administração dos empreendimentos privados. 
Na segunda metade do século XIX, surgiu o modelo de Administração Pública Burocrática que se apresentou como forma de estruturar as organizações, combater a corrupção e o nepotismo característico da anterior - Administração Pública Patrimonialista - que não distinguia o que era patrimônio público e os bens dos administradores. $O$ novo modelo trouxe consigo ideias de desenvolvimento profissional, hierarquia funcional, impessoalidade, formalismo e principalmente a adoção de controles administrativos das rotinas.

Os parâmetros da Administração Burocrática, evoluíram para a Administração Pública Gerencial como resposta à expansão das funções econômicas e sociais do Estado, tornando-se essencial reduzir custos e aumentar a qualidade dos serviços, priorizando o cidadão como beneficiário. Esse modelo constituiu em um avanço, pois buscou maior eficiência da Administração Pública, na execução de suas serventias aos cidadãos.

A função administrativa de controle e aplicabilidade compõe elemento fundamental para que a Administração Pública alcance seus objetivos, com vistas no cidadão. Essa função mostra-se útil para abonar a aplicação adequada, atender aos planos e políticas aprovadas para o setor público por meio dos orçamentos e programas de governo. Com isso, busca a efetividade dos serviços públicos (MEIRELLES, 2004, p. 620).

Essa fiscalização administrativa, orientada na defesa do interesse público, visa coibir e corrigir distorções administrativas, conforme ensina Di Pietro (2000, p. 575):

\footnotetext{
A finalidade do controle é assegurar que a Administração atue em consonância com os princípios que lhe são impostos pelo ordenamento jurídico, como os da legalidade, moralidade, finalidade pública, publicidade, motivação, impessoalidade; em determinadas circunstancias, abrange também o chamado controle de mérito e que diz respeito aos aspectos discricionários da atuação administrativa.Embora o controle seja atribuição estatal, o administrado participa dele na medida em que pode e deve provocar o procedimento de controle, não apenas na defesa de seus interesses individuais, mas também na proteção do interesse coletivo (Di Pietro, 2000, p. 575).
}

Didaticamente, o controle recebe classificações. Nesse ponto, Guerra (2003) afirma também que controle da administração é gênero, de onde se pode retirar várias espécies e, partindo dessa assertiva, chega-se a classificações do controle na Administração Pública 
quanto aos órgãos que exercita, ao objeto, ao momento de sua realização e quanto ao posicionamento do órgão controlador.

Da classificação de espécies de controle que leciona Lima (2007, p. 4-6), pode-se depreender os seguintes ensinamentos:

a) Quanto ao órgão que o exercita: administrativo, legislativo ou judicial. Controle Administrativo - corresponde ao exame que a Administração Pública faz sobre a sua conduta, quanto à legalidade ou ao mérito de seus atos, por iniciativa própria ou mediante provocação.

Controle Legislativo, dois tipos de controle: I) controle político: analisa aspectos de legalidade e de mérito;2) controle financeiro: art. 70 a 75 fiscalização contábil, financeira e orçamentária a cargo do Congresso Nacional com o auxílio do Tribunal de Contas da União.

Controle Judicial - monopólio da função judicial nas mãos do Poder Judiciário art. $5^{\circ}, \mathrm{XXXV}$, da CF - "a lei não excluirá da apreciação do Poder Judiciário lesão ou ameaça a direito." 5.2 Limites: análise da legalidade (art. 5으, LXXIII e 37, da CF). Poder Judiciário não pode invadir o mérito do ato administrativo, determinado pela Administração Pública. Controle para movimentar o Poder Judiciário: Remédios constitucionais: Habeas Corpus - art. $5^{\circ}$, LXVIII; Habeas Data - art. 5ㅇ, LXXII; Mandado de Injunção - art. 5ㅇ, LXXI; Mandado de Segurança individual - art. $5^{\circ}$, LXIX; Mandado de Segurança coletivo - art. $5^{\circ}$, LXX; Ação Popular - art. 5으, LXXIII; Ação Civil Pública - art. 129, III; Controle de constitucionalidade.

b) Quanto ao objeto da atividade administrativa a ser controlada: I) controle de legalidade: exercido pelos três Poderes; 2) controle de mérito: exercido pela própria Administração.

c) Quanto ao momento em que se efetua: $\mathrm{I}$ ) controle prévio (a priori) - controle preventivo, pois busca impedir a expedição de ato ilegal ou contrário ao interesse público; 2) controle concomitante - exercido ao mesmo tempo em que se realiza a atividade; 3) controle posterior - busca reexaminar atos já praticados, para corrigilos, desfazê-los ou apenas confirmá-los.

d) Quanto à localização do órgão controlador: I) controle interno: controle que cada um dos Poderes exerce sobre sua própria atividade administrativa; 2) controle externo: controle exercido por um dos Poderes sobre o outro ou controle da Administração.

O artigo 7I da Constituição Federal, prever a fiscalização contábil, financeira e orçamentária a cargo do Congresso Nacional, com o auxílio do Tribunal de Contas da União. Note-se que na Constituição de 1988, quis-se um Controle Externo capaz de se comunicar diretamente com a sociedade, uma vez que a estrutura nela exposta traduz um meio de acompanhamento das atividades administrativas do Estado Brasileiro, com vista à cidadania que representa idealmente a vontade da população. 


\subsection{LEI DE RESPONSABILIDADE FISCAL - DA TRANSPARENCIA, CONTROLE E FISCALIZAÇÃO}

No histórico administrativo brasileiro de controle, pode-se afirmar que houve três picos nos ajustes legais, a saber: o Decreto-Lei no 200 , de 25 de fevereiro de 1967 , ainda em vigor, que classifica o controle como um dos princípios fundamentais da administração pública e, em seu artigo 13 , dá a abrangência e a definição ao termo senão vejamos; $\mathrm{A}$ Constituição Federal de 1988, em seu artigo 70 a 75 , tratam de controle; e a Lei de Responsabilidade Fiscal- LRF, Lei Complementar no ıо de 2000.

A LRF, além de tratar de controle, trouxe referência à transparência, tratando como algo a ser buscado pela divulgação de relatórios de fiscalização O capítulo IX da LRF referese à transparência, controle e fiscalização e estabelece regras e procedimentos para a confecção e divulgação de relatórios e demonstrativos de finanças públicas, a fiscalização e o controle, visando permitir ao cidadão avaliar através da informação disponibilizada em relatórios, o grau de sucesso obtido pela administração das finanças públicas.

A mesma LRF estabeleceu em seu artigo 48 o seguinte dispositivo:

São instrumentos de transparência da gestão fiscal, aos quais será dada ampla
divulgação, inclusive em meios eletrônicos de acesso público: os planos,
orçamentos e leis de diretrizes orçamentárias; as prestações de contas e o respectivo
parecer prévio; o Relatório Resumido da Execução Orçamentária e o Relatório de
Gestão Fiscal; e as versões simplificadas desses documentos.
Parágrafo único. A transparência será assegurada também mediante incentivo à
participação popular e realização de audiências públicas, durante os processos de
elaboração e de discussão dos planos, lei de diretrizes orçamentárias e orçamentos.

A transparência é, ainda, assegurada pelo incentivo à participação popular e pela realização de audiências públicas, tanto durante a elaboração como no curso da execução dos planos da lei de diretrizes orçamentárias e dos orçamentos. Todos os relatórios devem ser divulgados, em veículos de comunicação de amplo acesso público.

O Relatório Resumido da Execução Orçamentária (RREO) é exigido pela CF/88, que estabelece em seu art. I65, parágrafo $3^{\circ}$, que o Poder Executivo o publicará, até trinta dias após o encerramento de cada bimestre. 
A União já o divulga, há vários anos mensalmente. O objetivo dessa periodicidade é permitir que, cada vez mais, a sociedade, por meio dos diversos órgãos de controle, conheça, acompanhe e analise o desempenho da execução orçamentária dos governos.

A LRF especifica os parâmetros necessários à elaboração do Relatório Resumido da Execução Orçamentária. Sua elaboração e publicação são de responsabilidade do Poder Executivo. As informações deverão ser elaboradas a partir da consolidação de todas as unidades gestoras, no âmbito da administração direta, autarquias, fundações, fundos especiais, empresas públicas e sociedades de economia mista. A Lei estabelece ainda que ao final de cada quadrimestre, será emitido o Relatório de Gestão Fiscal pelos titulares dos Poderes Executivo, Legislativo (incluído o Tribunal de Contas), Judiciário e Ministério Público, prestando constas sobre a situação de tudo que está sujeito a limites e condições como, despesas com pessoal, dívida, operações de crédito, ARO, e medidas corretivas implementadas se os limites forem ultrapassados. Caso contrário, o órgão público ficará impedido de receber transferências voluntárias e contratar operações de crédito. $\mathrm{O}$ art. 67 da Lei de Responsabilidade Fiscal diz:

O acompanhamento e a avaliação, de forma permanente, da política e da operacionalidade da gestão fiscal serão realizados por conselho de gestão fiscal, constituído por representantes de todos os Poderes e esferas de Governo, do Ministério Público e de entidades técnicas representativas da sociedade.

Observa-se que no artigo transcrito acima, a própria Lei cria um mecanismo de controle na forma de um Conselho de gestão fiscal, cuja competência é harmonizar e coordenar os entes da Federação, disseminar boas práticas fiscais, adotar normas de consolidação das contas públicas e divulgar estudos e análises. A LRF expressamente ressalta a temática do controle e transparência na administração pública, aponta ainda para as chamadas tecnologias da informação, que podem proporcionar maior interação das instituições sociais e a administração pública.

Nesse ponto, com a rede de informação pela internet, o controle social e a transparência, podem ser construídos e com isso o Estado encontra reforço na sua nova forma de legitimação de poder. O Estado deve propor ao cidadão as maneiras para que se firme uma sociedade mais participativa e os instrumentos tecnológicos que carregam as 
informações devem ser de alguma forma, colocados à disposição da sociedade, pois só assim pode existir o controle social sobre a administração pública e se efetivará a transparência dos seus atos.

Essas novas demandas tecnológicas de controle devem pautar a sociedade para o fortalecimento das instituições democráticas e abrir caminhos mais definitivos para a participação popular. Norberto Bobbio as entende como novos direitos que o desenvolvimento da técnica, a transformação das condições econômicas e sociais, a ampliação dos conhecimentos e a intensific ação dos meios de comunicação podem produzir mudanças na organização da vida humana e das relações sociais.

O campo dos direitos sociais está em contínuo movimento: assim, como as mudanças de proteção social nasceram com a revolução industrial, é provável que o rápido desenvolvimento técnico e econômico traga consigo novas demandas que hoje não somos capazes nem de prever. (BOBBIO, apud, ROVER, 2004. p. 159).

É nesse sentido que, mais do que em qualquer outra época se pode falar em novos direitos e isso inclui os relativos à relevância da transparência das ações públicas e iniciativas governamentais, por meios de instrumentos capazes de retratar e impulsionar o momento atual para aumentar a eficiência e eficácia governamental.

O custo reduzido de acesso à internet e os recursos tecnológicos disponíveis podem constituir fatores para consultas mais frequentes, viabilizando realmente a democracia participativa no País. A internet, como efetivo controle social, tornou-se mais próxima da realidade na medida em que o próprio Tribunal de Contas da União passou a utilizar-se desse mecanismo.

A atividade principal do Tribunal é o controle externo da administração pública e da gestão dos recursos públicos federais, sendo a sua missão assegurar a efetiva e regular gestão dos recursos públicos, em benefício da sociedade. A visão que norteia as atividades desse órgão busca torná-lo uma instituição de excelência no controle e contribuir para o aperfeiçoamento da administração.

A homepage do TCU oferece uma gama de informações que possibilitam o efetivo acompanhamento por parte da sociedade das ações administrativas executadas pelos órgãos do Estado. 
Existe a possibilidade de que a própria sociedade auxilie o TCU na identificação da má aplicação dos recursos públicos, na medida em que ela é a destinatária primeira das ações do governo, na real exteriorização do princípio constitucional da participação popular na observância da moralidade administrativa, por meio de denúncia, atendendo plenamente aos objetivos de alcançar maior transparência. A denúncia deve se referir a alguém que seja responsável por recursos federais. Assim, é possível tomar conhecimento de que toda entidade gestora de recursos públicos está sujeita à fiscalização iniciada por meio de denúncia.

A Lei № 9. 755, de 16/12/1998, ao dispor sobre a criação de homepage na Internet, pelo Tribunal de Contas da União, para divulgação dos dados e informações, criou normas jurídicas necessárias para o cumprimento do previsto no Art. 37 da CF/88, no que diz respeito ao princípio da transparência e publicidade, neste novo modo de organização da sociedade e do Estado, qual seja, o modo informativo ou em rede.

A partir de 1995, concomitante com o crescimento da Internet no País, aumentou grandemente a quantidade de "sites" do Governo Federal na rede. Nos anos recentes, a variedade de informações aumentou, não somente no nível Federal, mas especialmente no nível estadual. Por outro lado, o acesso a tais informações, no âmbito do Governo Federal, foi sistematizado pelo Ministério do Planejamento, através do portal http://www.redegoverno.gov.br. Há ampla variedade de informações governamentais para o cidadão na Internet.

As principais linhas de ação do Poder Executivo Federal em tecnologia da informação e comunicação estão estruturadas caminhando em direção a um governo eletrônico promovendo a universalização do acesso aos serviços, a transparência de suas ações, a integração de redes e o alto desempenho dos seus sistemas. A meta é colocar o governo ao alcance de todos, ampliando a transparência das suas ações e incrementando a participação cidadã.

Com a Lei de Responsabilidade Fiscal, a Tecnologia da Informação se torna uma ferramenta de fiscalização dos atos praticados pela administração pública. Desde maio passado de 2002, os balanços com todas as despesas e receitas do Poder Público estão sendo divulgados na Internet, para acompanhamento pela sociedade.

A transparência requerida pela LRF, bem como o exíguo prazo de prestação de contas dos atos financeiros, exige não apenas controle, mas velocidade. Por outro lado, diante da natureza capilar de todos os passos que compõem o fluxo de recursos, o controle e acompanhamento com integração das informações em tempo real só são possíveis por meio da Tecnologia da Informação (ROVER, 2004, p. 172). 
A intenção da LRF é justamente aumentar a transparência na gestão do gasto público, permitindo que os mecanismos de mercado e o processo político sirvam como instrumento de controle e punição dos governantes que não agirem de maneira correta. Deve ser, então, vista como um instrumento forte e eficaz, para introduzir, na prática das finanças públicas, um comportamento mais dinâmico e coerente com os superiores interesses da população. As informações estão tratadas. Cabe agora a sua interpretação para a aprovação ou reprovação dos governantes.

\section{CONSIDERAÇÕES FINAIS}

Durante a investigação sobre a temática "o Sistema de Controle Externo da Administração Pública Federal” observou-se que há um empenho do legislador brasileiro em promover a transparência pública, seja como algo planejado, seja como resultado de produção legislativa que chegue a esse importante instrumento de cobrança social sobre a atuação do governo.

Notou-se que o Tribunal de Contas da União, historicamente, com a sua atuação, busca melhorias nos resultados da aplicação dos recursos públicos, com vistas aos princípios constitucionais atinentes à Administração Pública. Contudo, não somente o TCU trabalha no sentido de divulgar ações e coibir eventuais desvios de recursos públicos, pois, ao longo da pesquisa, e até pelo desempenho profissional, o pesquisador encontrou alguns sites de internet que difundem atividades do setor público com intuito de promover a transparência administrativa, e que são citados nesse trabalho.

Contudo, sendo o TCU órgão técnico de apoio do Poder Legislativo na função de fiscalizador das ações do Poder Executivo, na manifestação do mecanismo de freios e contrapesos, característica da harmonia entre os poderes no Estado brasileiro, também o Poder Executivo, por iniciativa própria, promove a visibilidade de suas ações. Tanto o é, que criou a Controladoria Geral da União- CGU, com vistas à transparência administrativa. Isso demonstra a vontade política do governo de viabilizar a concretude da transparência pública. 
Neste contexto se pode afirmar que o presente estudo poderá contribuir substancialmente no debate sobre os instrumentos de controle externo da gestão administrativa para o alcance da transparência na Administração Pública. A contribuição se efetivará no sentido de proporcionar as informações e ciência dos atos praticados pelos administradores, levando clareza aos interessados pelo assunto, que em sentido lato seria a própria sociedade.

Conforme explanado ao longo da pesquisa, a Administração Pública possui Controle Externo, representado pelo Tribunal de Contas da União, como auxiliar do Poder Legislativo no controle das atividades do Poder Executivo, a quem cabe a Administração Pública. Portanto, o presente estudo pode servir de base para novas pesquisas, fornecendo, assim, com toda a comunidade acadêmica e sociedade em geral.

\section{REFERÊNCIAS BIBLIOGRÁFICAS}

BOBBIO, Norberto. A era dos direitos. tradução. Carlos Nelson Coutinho. ıo. ed. Rio de Janeiro: Campus: 1992.

BRASIL. Constituição (I988). Brasília: Senado Federal, 2007.

Lei Complementar no 101 , de 04 de maio de 2000 (Lei de Responsabilidade Fiscal). Estabelece normas públicas voltadas para a responsabilidade na gestão fiscal e dá outras providências. Disponível em: $\langle$ HTTP://www.senado.gov.br $\rangle$. Acesso em: 25 de julho de 2019.

Regimento Interno do Tribunal de Contas da União (Resolução $\mathrm{n}^{\circ}{ }^{\mathrm{O}} \mathrm{55} / 2002$ ) Disponível em: < HTTP://www.tcu.gov.br $>$. Acesso em: 25 de julho de 2019.

CHIAVENATO, Idalberto. Introdução à teoria geral da administração. 6. ed. Rio de Janeiro: Editora Campus, 2000.

DI PIETRO, Maria Sylvia Zanella. Direito Administrativo. 12. ed. São Paulo: Editora Atlas, 2000.

FERNANDES, José. Técnicas de Estudo e Pesquisa. 6.ed. Goiânia: Kelps, 2002.

GUERRA, Evandro Martins. Os Controles Externo e Interno da Administração Pública e os Tribunais de Contas. Belo Horizonte: Fórum, 2003.

LIMA, Luiz Henrique. Controle Externo: teoria, legislação, jurisprudência e questões de concursos. Rio de Janeiro: Editora Elservier, 2007.

MAIA, Lauro Augusto Moreira. Novos paradigmas do direito civil. Curitiba-PR: Juruá, 2007. 
MARTINS JÚNIOR, Wallace Paiva. Transparência Administrativa: publicidade, motivação e participação popular. São Paulo: Editora Saraiva, 2004.

MEIRELlES, Hely Lopes. Direito Administrativo Brasileiro. 29. ed. São Paulo: Editora Malheiros, 2004.

MEZZAROBA, Orides e MONTEIRO, Cláudia Servilha. Manual de Metodologia da Pesquisa no Direito. 3. ed. São Paulo: Editora Saraiva, 2006.

MORAIS, Alexandre de. Direito constitucional administrativo. São Paulo: Atlas, 2002.

PEREIRA, Luiz Carlos Bresser. Estratégia e estrutura para um novo Estado. Revista do Serviço Público/Fundação Escola Nacional de Administração Pública - vi. n.ı- ano 48 (janabr/1997). Brasília: ENAP, 1997.

ROVER, Aires José. Direito e informática. Barueri-SP: Editora Manole, 2004.

SILVA, José Afonso da. Curso de Direito Constitucional Positivo. 28. ed. São Paulo: Editora Malheiros, 2007.

O sistema representativo, democracia semidireta e democracia participativa. Publicado na Revista do Advogado no 73, p 9 SPECK, Bruno Wilhelm. Caminhos da transparência: análise dos componentes de um sistema nacional de integridade. Campinas, SP: Unicamp, 2002.

TROSA, Sylvie. Gestão Pública por Resultado: quando o Estado se compromete. tradução: Maria Luíza de Carvalho. Rio de Janeiro: Revan: Brasília. DF: ENAP, 200 . 